\title{
Three-dimensional Monte Carlo calculation of some nuclear parameters
}

\author{
Mehtap Günay ${ }^{*}$, Gökmen Şeker \\ İnönü University, Science and Art Faculty, Physics Department, Malatya, Turkey
}

\begin{abstract}
In this study, a fusion-fission hybrid reactor system was designed by using 9Cr2WVTa Ferritic steel structural material and the molten salt-heavy metal mixtures 99-95\% $\mathrm{Li}_{20} \mathrm{Sn}_{80}+1-5 \% \mathrm{RG}-\mathrm{Pu}, 99-95 \%$ $\mathrm{Li}_{20} \mathrm{Sn}_{80}+1-5 \% \mathrm{RG}-\mathrm{PuF}_{4}$, and $99-95 \% \mathrm{Li}_{20} \mathrm{Sn}_{80}+1-5 \% \mathrm{RG}-\mathrm{PuO}_{2}$, as fluids. The fluids were used in the liquid first wall, blanket and shield zones of a fusion-fission hybrid reactor system. Beryllium $(\mathrm{Be})$ zone with the width of $3 \mathrm{~cm}$ was used for the neutron multiplication between the liquid first wall and blanket. This study analyzes the nuclear parameters such as tritium breeding ratio $(T B R)$, energy multiplication factor $(M)$, heat deposition rate, fission reaction rate in liquid first wall, blanket and shield zones and investigates effects of reactor grade Pu content in the designed system on these nuclear parameters. Threedimensional analyses were performed by using the Monte Carlo code MCNPX-2.7.0 and nuclear data library ENDF/B-VII.0.
\end{abstract}

\section{Introduction}

The fuels used in hybrid reactor systems are generally deuterium-tritium (D-T) or deuterium-deuterium (D-D) fuels. When D-T fuel enters the fusion reaction, 14.1 $\mathrm{MeV}$ fusion neutrons and $3.5 \mathrm{MeV}$ alpha particles are released. The plasma is surrounded by a wall made of fertile material, which cannot undergo the fusion reaction with thermal neutrons, but can undergo conversion with high energy neutrons, such as the 14.1 $\mathrm{MeV}$ neutrons produced by the fusion reaction. Thus, the high energy fusion neutrons convert fertile materials to fissile fuel, fission neutrons, and produce energy. The hybrid reactor produces 30 times more nuclear fuel per nuclear energy quantity than fast reactors [1-6].

In this study, a hybrid reactor system was designed. The hybrid reactor system can generate secure energy in large quantities with D-T fuel usage and subcritical study. Furthermore, it enables the production of a selfsufficient fuel for the reactor through the reaction of the neutrons released by the plasma. Reactor-grade (RG) plutonium is found in spent nuclear fuel. Isotopic distribution of RG-Pu has composition $1 \%{ }^{238} \mathrm{Pu}, 62 \%$ ${ }^{239} \mathrm{Pu}, 24 \%{ }^{240} \mathrm{Pu}, 8 \%{ }^{241} \mathrm{Pu}$ and $5 \%{ }^{242} \mathrm{Pu}$ [7]. The reactor-grade $\mathrm{Pu}$ in present nuclear power stations as fuel can use to reduce the trans-uranium content of spent nuclear fuel. in this study, radioactive materials with a plutonium additive were used in the hybrid reactor system to reduce the amount of reactor grade $\mathrm{Pu}$ used.

\section{Method}

\subsection{Numerical Calculations}

Hybrid reactor system used in the study is in the shape of a torus. The radial structure of designed the hybrid reactor system is shown in Table 1. Calculation of all the parameters of the fission and fusion reactors and other areas of nuclear technology depend on the cross-section data. The data of the ENDF/B-VII libraries are very important for theoretical calculations [8-10]. Analysis was performed for neutron wall loading $10 \mathrm{MW} / \mathrm{m}^{2}$ and fusion power $4000 \mathrm{MW}$.

Table 1. The radial build of the hybrid reactor system design

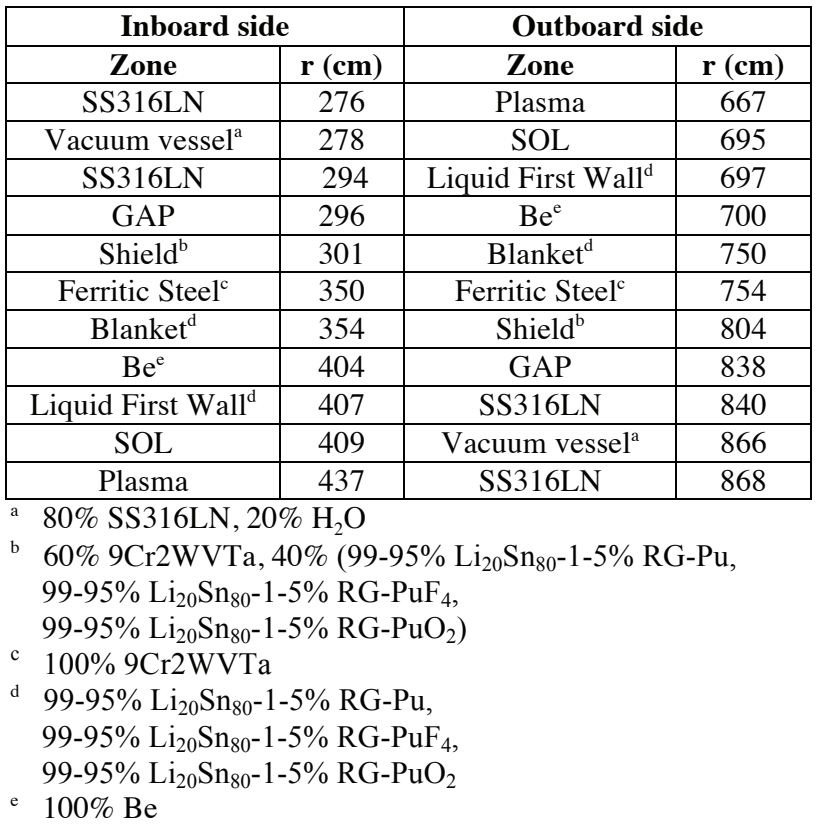

\subsection{Tritium Breeding}

The tritium breeding ratio (TBR) is defined as the ratio of the rate of tritium production in the system to the rate of tritium burning in the plasma. The hybrid reactor has to

Corresponding author: mehtap.gunay@inonu.edu.tr 
breed the tritium it requires $[11,12]$. Tritium is bred through the reaction of lithium with neutrons. The ${ }^{6} \mathrm{Li}(\mathrm{n}, \alpha) \mathrm{T}$ reaction is produced with thermal neutrons, and the ${ }^{7} \mathrm{Li}\left(\mathrm{n}, \alpha \mathrm{n}^{\prime}\right) \mathrm{T}$ reaction with fast neutrons. In the hybrid reactor system, the working liquid must be a lithium-containing medium to provide adequate tritium so that the plasma is self-sustaining and the fusion is a renewable energy source. the required $T B R$ for a fission reactor conceptual design must be 1.1 [11-15]. TBR can be given as follows:

$$
\begin{gathered}
T B R=\mathrm{T}_{6}+\mathrm{T}_{7} \\
\mathrm{~T}_{6}=\iint \Phi \cdot \Sigma_{(\mathrm{n}, \alpha) \mathrm{T}} \mathrm{dE} \mathrm{dV}, \text { for }{ }^{6} \mathrm{Li} \\
\mathrm{T}_{7}=\iint \Phi . \Sigma_{\left(\mathrm{n}, \mathrm{n}^{\prime} \alpha\right) \mathrm{T}} \mathrm{dE} \mathrm{dV}, \text { for }{ }^{7} \mathrm{Li} .
\end{gathered}
$$

In this study, $\mathrm{Li}_{20} \mathrm{Sn}_{80}$ molten salt was used, which has low melting temperatures and low vapor pressure, to acquire sufficient tritium breeding.

\subsection{Energy Multiplication Factor, Heat Deposition Rate and Fission Reaction Rate}

The energy multiplication factor $M$ is the ratio of nuclear heating and source neutron energy incident on the first wall [16]. The energy produced must exceed the energy produced by the plasma. To obtain high thermal power, the $M$ value should be as large as possible. It is desirable that $M$ is greater than 1.2 in a D-T fueled reactor [17]. $M$ can be defined as follows:

$$
\begin{gathered}
M=\left[\left(200 \mathrm{x}\left(\Phi . \Sigma_{\mathrm{f}}\right)+4.784 \mathrm{xT}_{6}-2.467 \mathrm{xT}_{7}\right) / 14.1\right]+1 \\
\left(\Phi . \Sigma_{\mathrm{f}}\right)=\iint \Phi . \Sigma_{\mathrm{f}} \mathrm{dE} \mathrm{dV}, \text { total fission rate. }
\end{gathered}
$$

The contributions of the neutron flux, fission, and other reactions to the integrated $M$ and heat deposition rate are very important. The main contributions to the integrated $M$ and heat deposition rate are from the neutron flux, the fission reaction of plutonium isotopes, and the exothermic ${ }^{6} \mathrm{Li}(\mathrm{n}, \alpha) \mathrm{T}$ reaction of $\mathrm{Li}_{20} \mathrm{Sn}_{80}$ molten salt.

\section{Numerical Results}

In this study, the fluids were composed of molten salt $\mathrm{Li}_{20} \mathrm{Sn}_{80}$ as the main constituent with increased mole fractions of heavy metals, $1-5 \%$ RG-Pu, RG-PuF 4 , RG$\mathrm{PuO}_{2}$. The fluids used in order to decrease amount of reactor grade $\mathrm{Pu}$ were used in the liquid first wall, blanket and shield zones of hybrid reactor system.

Fig. 1 shows the TBR in the liquid first wall, blanket and shield regions per fusion source neutron for the various mixture compositions of molten salt and heavy metals. The increasing heavy metals contents means decreasing the $\mathrm{Li}$ that produces tritium. In Fig. 1, the $T B R$ decreases due to decreasing the $\mathrm{Li}$ that produces tritium with an increase in the heavy metals contents.

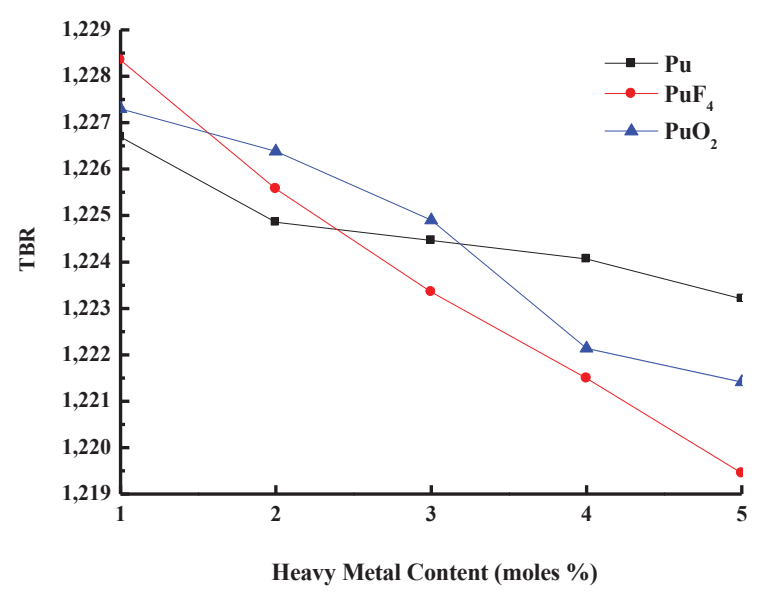

Fig. 1. The variation of the $T B R$ value versus the mixture components of $\mathrm{Li}_{20} \mathrm{Sn}_{80}, \mathrm{RG}-\mathrm{Pu}, \mathrm{RG}-\mathrm{PuF} \mathrm{F}_{4}, \mathrm{RG}-\mathrm{PuO}_{2}$ in the liquid first wall, blanket and shield zones.

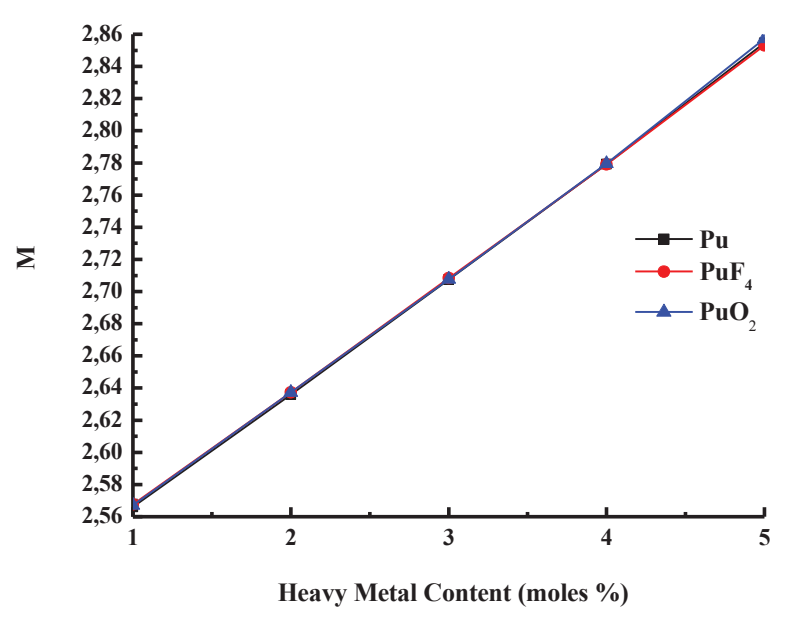

Fig. 2. The variation of the energy multiplication factor $M$ versus the mixture components of $\mathrm{Li}_{20} \mathrm{Sn}_{80}, \mathrm{RG}-\mathrm{Pu}, \mathrm{RG}-\mathrm{PuF}_{4}$, $\mathrm{RG}-\mathrm{PuO}_{2}$ in the liquid first wall, blanket and shield zones.

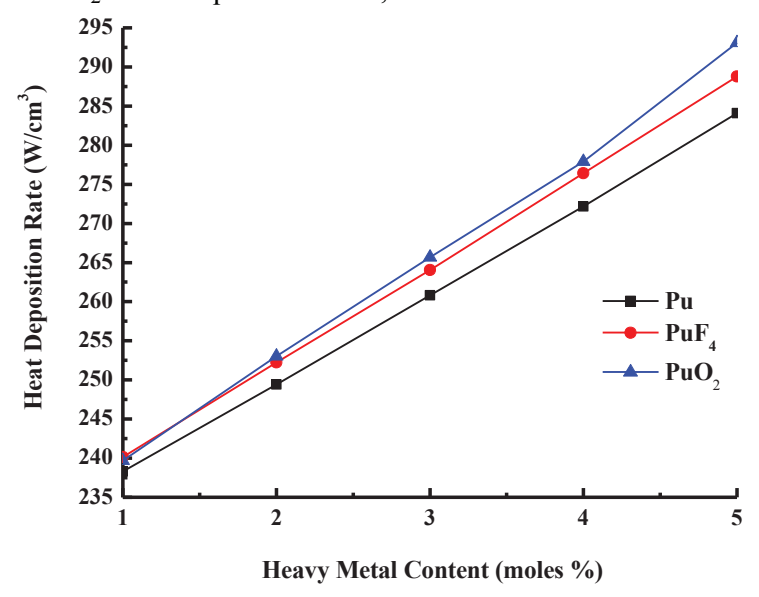

Fig. 3. The variation of the heat deposition rate versus the mixture components of $\mathrm{Li}_{20} \mathrm{Sn}_{80}, \mathrm{RG}-\mathrm{Pu}, \mathrm{RG}-\mathrm{PuF}_{4}, \mathrm{RG}-\mathrm{PuO}_{2}$ in the liquid first wall, blanket and shield zones.

Fig. 2 and Fig. 3 shows the energy multiplication factor $M$ and the heat deposition rate in the liquid first wall, blanket and shield regions per fusion source neutron for the various mixture compositions of molten salt and heavy metals. In Fig. 2 and Fig. 3, it was found 
that $M$ and the heat deposition rate increases linearly for increase of fission reaction rate with increasing of RG$\mathrm{Pu}, \mathrm{RG}-\mathrm{PuF}_{4}, \mathrm{RG}-\mathrm{PuO}_{2}$ heavy metals contents. The $M$ value was obtained to be between 2.56 and 2.87 values. This value is greater than 1.2 value desirable of $M$.

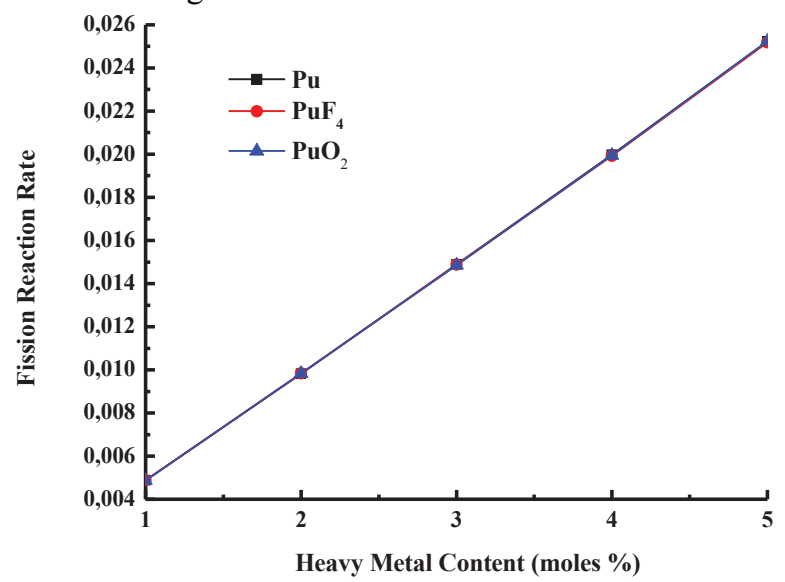

Fig. 4. The variation of the fission reaction rate versus the mixture components of $\mathrm{Li}_{20} \mathrm{Sn}_{80}, \mathrm{RG}-\mathrm{Pu}, \mathrm{RG}-\mathrm{PuF}_{4}, \mathrm{RG}-\mathrm{PuO}{ }_{2}$ in the liquid first wall, blanket and shield zones.

Fig. 4 shows the variation of the fission reaction rate versus the mixture components of $\mathrm{Li}_{20} \mathrm{Sn}_{80}, \mathrm{RG}-\mathrm{Pu}, \mathrm{RG}$ $\mathrm{PuF}_{4}, \mathrm{RG}-\mathrm{PuO}_{2}$ in the liquid first wall, blanket and shield zones. Fig. 4 shows that the fission reaction rate increases linearly in the liquid first wall, blanket and shield regions with increasing of the heavy metals contents in mole percent.

\section{Conclusions}

In the study the effect of reactor grade $\mathrm{Pu}$ content in the designed system on three-dimensional neutronic measurements, such as $T B R, M$, heat deposition rate and fission reaction rate, was investigated.

In the calculation was observed that the $T B R$ decreases with an increase in the heavy metals contents. The increasing heavy metals contents means decreasing the $\mathrm{Li}$ that produces tritium. This decrease between minimum and maximum rates of the heavy metals was obtained in approximately the same rate for RG-Pu, RG$\mathrm{PuF}_{4}, \mathrm{RG}-\mathrm{PuO}_{2}$. It was found that $T B R$ values calculated with increase of the heavy metals contents higher than 1.1 the limit value. It was found that the greatest contribution to TBR comes from $\mathrm{RG}-\mathrm{PuF}_{4}$ in around $1 \%$ of the heavy metal content.

In the calculation, it was observed that the $M$ and heat deposition rate increase with an increase in the heavy metal content for the selected fluids, owing to an increase of the fission reaction rate. All $M$ values found from selected fluids are too close to each other and are approximately two times higher than 1.2 limit value of $M$. The increase between the minimum and maximum heat deposition rates and $M$ values for the different heavy metals was approximately the same. It was found that the greatest contribution to $M$ and the heat deposition rate comes with a fluid content of $95 \%$ $\mathrm{Li}_{20} \mathrm{Sn}_{80}+5 \% \mathrm{RG}-\mathrm{PuO}_{2}$.
In conclusion, it was found that reactor grade $\mathrm{Pu}$ amount decrease and neutronic calculations yield desirable values when one uses fluids of $95 \% \mathrm{Li}_{20} \mathrm{Sn}_{80^{-}}$ $5 \% \mathrm{RG}-\mathrm{Pu}, \mathrm{RG}-\mathrm{PuF}_{4}, \mathrm{RG}-\mathrm{PuO}_{2}$, in comparison to the other ratios and types of fluids in the liquid first wall, blanket and shield zones.

\section{Acknowledgements}

This work was supported by İnönü University Research fund with the project number 2015/68.

\section{References}

1. S. Şahin, M. Übeyli, Energy Convers. Manage., 46, 3185 (2005)

2. H.M. Şahin, Ann. of Nucl. Energy, 34, 861 (2007)

3. B. Şarer, et al., Fusion Sci. Technol., 52, 107 (2007)

4. M. Günay, et al., Ann. of Nucl. Energy, 38(12), 2757 (2011)

5. M. Günay, et al., Ann. of Nucl. Energy, 55, 292 (2013)

6. M. Günay, et al., Ann. of Nucl. Energy, 63, 157 (2013)

7. IAEA, International Atomic Energy Agency, IAEA- TECDOC$1349(2003)$

8. B. Şarer, et al., Ann. of Nucl. Energy, 36, 417 (2009)

9. M. Günay, et al., Ann. of Nucl. Energy, 53, 59 (2013)

10. M. Günay, et al., Ann. of Nucl. Energy, 63, 432 (2014)

11. M. E. Sawan, et al., Fusion Engineering and Design, 81, 1131 (2006)

12. J. Jung, et al., Nuclear Technol./Fusion, 4, 361 (1983)

13. M. A. Abdou, et al., Fusion Technol., 9, 250 (1986)

14. W. Kuan, et al., Fusion Technol., 35, 309 (1999)

15. M. Z. Youssef, et al., Fusion Technol., 9, 286 (1986)

16. S. Şahin, et al., Energy Convers. Manage., 45, 1497 (2004)

17. A. H. Dhaba'an, et al., Progress in Nuclear Energy 29, 1 (1995) 